\title{
Influence of Antagonist Material on Fatigue and Fracture Resistance of Zirconia Crowns
}

\author{
${ }^{1}$ Department of Applied Dental Sciences, Faculty of Applied Medical \\ Sciences, Jordan University of Science and Technology, Irbid, \\ Jordan \\ 2Faculty of Mechanical Engineering, Esslingen University of Applied \\ Sciences, Esslingen, Germany \\ ${ }^{3}$ Faculty of Engineering and Built Environment, University of \\ Newcastle, Newcastle, Australia \\ Eur J Dent 2020;14:200-205
}

Noor Nawafleh ${ }^{1} \quad$ Abdel Raheem Bibars ${ }^{1} \quad$ Elina Al Twal ${ }^{1} \quad$ Andreas Öchsner ${ }^{2,3}$

Address for correspondence Noor Nawafleh, BSc, MDentTech, PhD, Department of Applied Dental Sciences, Faculty of Applied Medical Sciences, Jordan University of Science and Technology, Irbid 22110, Jordan (e-mail: nanawafleh@just.edu.jo).

\begin{abstract}
Keywords

- antagonist

- fatigue

- chewing simulation

- indenter material

- fracture resistance
\end{abstract}

Objective This study investigates the influence of the most commonly used indenter materials on fatigue survival and fracture resistance of zirconia crowns.

Materials and Methods A total of 40 zirconia crowns were prepared using computer-aided design (CAD)/computer-aided manufacturing (CAM) technology: 30 crowns were divided into three experimental groups of 10 specimens and the last 10 specimens acted as the control group. The experimental groups were subjected to chewing simulation with simultaneous thermocycling. Three indenter materials (steatite ceramic, stainless steel, and tungsten carbide) with identical diameter were used to load the specimens. All crowns were then subjected to single load to fracture test in universal testing machine. Load was applied vertically with a crosshead speed of $1 \mathrm{~mm} / \mathrm{min}$ until failure, and fracture load was recorded.

Statistical Analysis Normal distribution of data was confirmed using the ShapiroWilk test. Descriptive statistics including means and standard deviations were determined for all groups. Differences between groups were tested using Dunnett's test and paired sample $t$-test.

Results Chewing simulation for 1.2 million cycles resulted in $100 \%$ survival. The highest mean fracture load was recorded for the control group and the lowest one was for the group fatigued with stainless steel indenter. Chewing simulation statistically significantly $(p<0.05)$ reduced the mean fracture load of the crowns fatigued with stainless steel and steatite ceramic indenter. However, the mean fracture load for the crowns fatigued with tungsten carbide was not significantly different from that of the control group.

Conclusion Steatite ceramic and stainless steel indenters produced close results and significantly reduced fracture load of zirconia crowns. However, tungsten carbide indenter caused nonsignificant reduction in the fracture load of zirconia crowns.

\section{Introduction}

The increased pursuit for perfect dental restorations has led to the development of new dental ceramics competing in strength, durability and aesthetic capabilities., ${ }^{1,2}$ The availability of a large number of products makes the choice of the best possible material for a particular case difficult for clinicians because long-term performance of recent materials remains an open question. Therefore, more laboratory simulations and long-term clinical studies are needed to ensure favorable mechanical behavior and to estimate clinical performance of newly introduced restorative materials. 
Laboratory tests applied on ceramics create stress states and failure modes different from those observed in clinic ${ }^{3}$ because the mechanical behavior of a ceramic material varies according to the testing conditions. ${ }^{4}$ Simulating fatigue phenomenon of dental restorations has been valued as an appropriate testing method to predict the clinical performance of all-ceramic restorations. ${ }^{5-8}$ Hence, designing the in vitro studies as close as possible to the in vivo situation should be highly appreciated to produce a successful simulation. ${ }^{9}$ Reviewing fatigue studies shows substantial variations in testing setup; experimental variables such as indenter material and size, periodontal ligament simulation, abutment material, number of cycles, and thermocycling regime vary considerably. ${ }^{10-13}$ The influence of these variables on the results of the simulation studies has not been investigated sufficiently in the literature. Therefore, many studies tend to simulate all variables; however, others choose to simplify the design because of the difficulty in controlling and standardizing all testing parameters.

Material and form of loading indenter are some of the parameters that might influence testing results by affecting significantly the contact condition and load transfer in mechanical testing. ${ }^{12}$ Reviewing the relevant literature shows that stainless steel, tungsten carbide, ceramic, composite resin, and aluminum were commonly used antagonist materials. ${ }^{10,12}$ Some of these materials such as tungsten carbide have elastic modulus properties that are not even close to those of human teeth. Lithium disilicate ceramic or glass indenters have been used as antagonist material in previous studies, as they have elastic properties close to those of natural teeth. ${ }^{14,15}$ Composite resin indenter is recommended in other studies because they are able to cause a more homogeneous stress distribution in the ceramic structure than other indenter materials such as tungsten carbide or steel indenters. ${ }^{16}$ These materials are different in mechanical properties and the effect they can produce when used to load ceramic specimens. ${ }^{7,11,14,17,18}$ Therefore, this study investigates the influence of the most commonly used indenter materials (ceramic, stainless steel, or tungsten carbide) on fatigue survival and fracture resistance of zirconia crowns. We hypothesis that using different indenter materials will not significantly influence fatigue survival and fracture resistance of zirconia specimens.

\section{Materials and Methods}

A typodont mandibular first molar (Nissin Dental Products Inc.; Kyoto, Japan) was prepared with a $1.5 \mathrm{~mm}$ occlusal reduction, $1.0 \mathrm{~mm}$ proximal/axial wall reduction, and $0.5 \mathrm{~mm}$ chamfer finish-line depth. An impression of the unprepared tooth was initially made using vinyl polysiloxane impression material (3M ESPE; MN, United States), and sectioned to standardize the preparation thickness. Forty impressions of the master die were then made (3M ESPE; MN, United States) and poured with epoxy resin (Exakto-Form; Bredent, Germany) to produce 40 replicas of the master die.
The prepared tooth was scanned using a laboratory scanner (Ceramill Map 400; AmannGirrbach, Germany) and saved in stereolithography (STL) format. Design software (AmannGirrbach, Germany) was used to design the monolithic zirconia crown using the imported STL data. The amount of tooth reduction at different surfaces was used as a guide in designing the crown. Crowns were dry milled from presintered zirconia disks (Ceramill Zolid ht+, Amann Girrbach, Germany) using 5-axis milling machine (Ceramill Motion 2; Amann Girrbach AG, Germany), and sintered in the recommended sintering furnace (Ceramill Therm; Amann Girrbach AG), according to the manufacturer recommended program with a long-term cooling. Crowns were adhesively luted to the epoxy replicas using Multilink Automix (Ivoclar Vivadent; Schaan, Liechtenstein) as per the manufacturer's instructions. The die and the inner surface of the crown were steam cleaned and dried with compressed air. The fitting surfaces of the crowns were blasted with 25 to $70 \mu \mathrm{m} \mathrm{Al} 203$ at 1 bar and silanized with Monobond plus (Ivoclar Vivadent; Schaan, Liechtenstein) for 60 seconds. Cement was applied and crowns were seated using light finger pressure which increased gradually, simulating clinical procedures. Crowns were stored in water at $37^{\circ} \mathrm{C}$ for 7 days prior to testing.

To prepare the specimens for chewing simulation, a supporting material (coldautopolymerizing acrylic resin, Megadental, Büdingen, Germany) was poured around the master die, which was fixed in a standardized position in the chewing simulator's specimen cup. The supporting material covered the die up to $2.0 \mathrm{~mm}$ away from the finish line. Crowns were divided into four groups $(n=10)$; three groups were subjected to chewing simulation (CS4.8; SD Mechatronik, Feldkirchen-Westerham, Germany) for 1.2 million cycles as seen in -Fig. 1 and one group acted as control.

Loading force was set at $100 \mathrm{~N}$ with a loading frequency of $1.2 \mathrm{~Hz}$. Three spherical indenters made of steatite ceramic (Modulus of elasticity $80 \mathrm{GPa}$ ), stainless steel (Modulus of elasticity $200 \mathrm{GPa}$ ), and tungsten carbide (modulus of elasticity $650 \mathrm{GPa}$ ) with identical diameter of $6 \mathrm{~mm}$ were used to load the specimens in the chewing simulator. A new indenter was used for each specimen to ensure standardization in the loading conditions. Articulating paper was used to ensure the position of the indenter at the distobuccal cusp tip for each specimen (-Fig. 1). Then, the step motor of the chewing simulator was moved $0.5 \mathrm{~mm}$ lingual, making it the starting point because of the standardized position of the crowns in the specimen's cup. While applying the load, the indenter slides $0.3 \mathrm{~mm}$ lingually down the cusp's triangular ridge and leave the specimen surface with a vertical distance of $2 \mathrm{~mm}$. Thermocycling in distilled water (temperature extremes: $5^{\circ} \mathrm{C}$ and $55^{\circ} \mathrm{C}$, dwell time: 60 second, pause time: 15 second) was applied during testing, using computerized thermocycling unit (SD Mechatronik GmbH; Feldkirchen-Westerham, Germany).

After chewing simulation, specimens were checked for cracks or fractures using a stereomicroscope (M125; Leica 

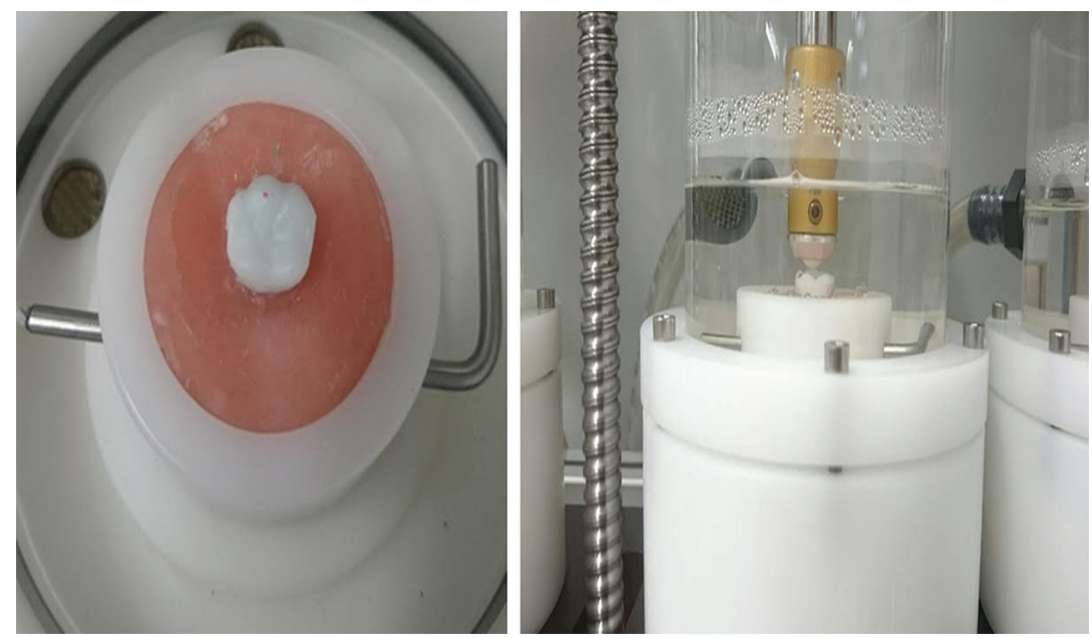

Fig. 1 Chewing simulations and indenter starting point identification.
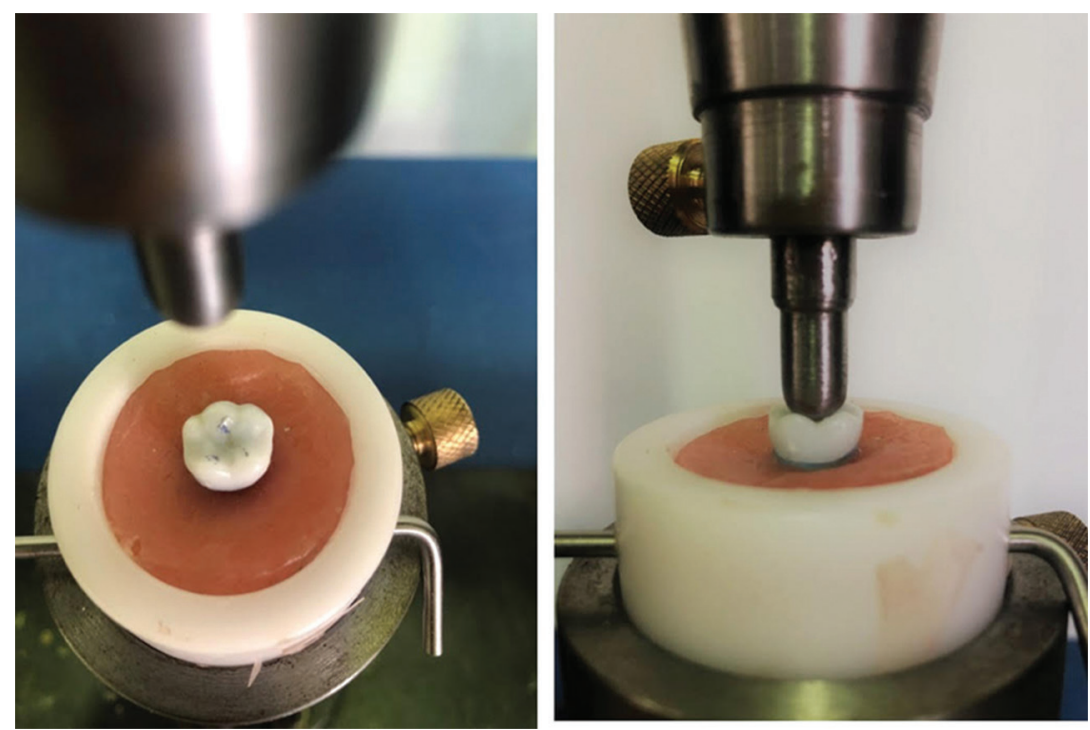

Fig. 2 Tripod contact of the indenter and tested crown during single load to fracture test.

Microsystems, Wetzlar, Germany) at 20× magnification. Crowns were then subjected to single load to fracture test in universal testing machine (Jinan Testing Equipment IE Corporation, China). Crowns were adjusted to achieve tripod contact with the indenter at the triangular ridges of the two lingual cusps and the distobuccal cusp as shown in -Fig. 2. Single load to fracture test was applied using spherical stainless steel indenter with $8 \mathrm{~mm}$ diameter. Load was applied vertically with a crosshead speed of $1 \mathrm{~mm} / \mathrm{min}$ until failure, and fracture load was recorded in Newton.

SPSS statistical package 23.0 (SPSS Inc., Chicago, IL, USA) was used for statistical analysis of the fracture load data. Normal distribution of data was confirmed using the Shapiro-Wilk test. Descriptive statistics including means and standard deviations were determined for all groups. Dunnett's test was used to test the differences between the experimental and control groups, and paired sample $t$-test was used to test the difference between the different combinations of the experimental groups ( - Table $\mathbf{1}$ ). For all statistical analyses, the level of significance was set at $95 \%$.

Table 1 Fracture load results in Newton and statistical significance between experimental and control groups

\begin{tabular}{|l|l|}
\hline Antagonist group & Mean (standard deviation) \\
\hline Control (no fatigue) & $4053(378)^{\mathrm{A}}$ \\
\hline Stainless steel & $3004(1086)^{\mathrm{B}, \mathrm{a}}$ \\
\hline Steatite ceramic & $3032(603)^{\mathrm{C}, \mathrm{a}}$ \\
\hline Tungsten carbide & $3440(609)^{\mathrm{A}, \mathrm{a}}$ \\
\hline
\end{tabular}

Note: Different capital superscripts indicate heterogeneous subsets compared with the control $(p<0.05)$. Similar small superscripts indicate homogeneous subsets when comparing the experimental groups $(p>0.05)$. 


\section{Results}

Chewing simulation for 1.2 million cycles with simultaneous thermocycling between $5^{\circ}$ and $55^{\circ} \mathrm{C}$ resulted in $100 \%$ survival; no cracks or fractures were observed after finishing the test. Failure of the monolithic zirconia crowns after single load to fracture test exhibited cohesive bulk fracture, including the whole thickness of the crowns, and showing different fracture paths with different numbers of fractured pieces.

The highest mean fracture load recorded was for the control group and the lowest one was for the group fatigued with stainless steel indenter ( $\mathbf{- T a b l e ~ 1 ) . ~ I n ~ c o m p a r i s o n ~ w i t h ~}$ the control group, chewing simulation for 1.2 million cycles statistically significantly $(p<0.05)$ reduced the mean fracture load by $26 \%$ for the crowns fatigued with stainless steel indenter, and by $24 \%$ for the crowns fatigued with steatite ceramic indenter. On the contrary, the mean fracture load for the crowns fatigued with tungsten carbide indenter was not significantly different from that of the control group with a reduction of only $15 \%$. Surprisingly, comparing postfatigue fracture load across indenter groups showed no significant difference between any of the combinations.

\section{Discussion}

This study suggested the following two hypotheses:

1. Indenter materials have no effect on in vitro fatigue survival (1.2 million cycles) of zirconia crowns.

2. Indenter materials have no effect on fracture resistance of fatigued zirconia crowns.

Chewing simulation for 1.2 million cycles resulted in 100\% survival. Stereomicroscope observations revealed no cracks or fractures after finishing the test. Therefore, hypothesis 1 was accepted. Fatigue in water with thermocycling significantly reduced the fracture load of zirconia crown fatigued with ceramic and stainless steel indenters. However, using tungsten carbide indenters in chewing simulation did not result in a statistically significant reduction in the fracture load of the specimens. Therefore, hypothesis 2 was rejected. The current study found that when indenters with lower modulus of elasticity values (stainless steel and steatite ceramic) were used in applying fatigue loading, a significant reduction in fracture load of the specimen occurred. The reduction in the fracture load was $26 \%$ and $24 \%$, respectively. Surprisingly, comparing the experimental groups showed no statistically significant difference between any combinations. These findings agree with those of Rosentritt et al ${ }^{11}$ in which a significant reduction in the fracture load of the specimens occurred after fatigue with steatite spheres and natural teeth antagonists compared with the unfatigued control group. Additionally, similar to the study in hand, the difference in fracture load between different indenter groups was insignificant. Rosentritt et al. ${ }^{11}$ concluded that the difference in antagonist material (difference in the elastic modulus) led to superficial changes with a small influence of the fracture resistance. These superficial changes, however, may lead to sudden and catastrophic failures due to crack growth and increasing wear, which are further induced by hydrolytic attacks in the aqueous oral environment. ${ }^{14,19}$ This may indicate that with prolonged simulation, the influence of the indenter material might be more noticeable.

This study showed that tungsten carbide indenter insignificantly reduced the fracture load of the fatigued specimens compared with the control group by only $15 \%$, thus reducing the effect of mechanical and thermal cycling compared with other indenter groups. In a recent study, Miranda et $\mathrm{al}^{16}$ evaluated the effect of using different loading pistons (epoxy resin, stainless steel and tungsten carbide) on fatigue survival ( 2 million cycles) of computer-aided design (CAD)/ computer-aided manufacturing (CAM) feldspathic porcelains. The group fatigued with tungsten carbide piston showed the highest survival rate (60\%), followed by the stainless steel piston group (40\%), and, finally, the epoxy resin piston group where only one specimen survived the fatigue test in this group.

Antagonists such as steatite and stainless steel may change form during loading which necessitates replacement, especially steel indenters which might get seriously abraded, producing sharp etches. ${ }^{12,20}$ Such deformation can cause wear and damage to the opposing surface. ${ }^{21}$ On the other hand, tungsten carbide antagonist is less susceptible to change in form and dimensions due to its high-modulus of elasticity. ${ }^{12}$ The aforementioned observations by previous studies were also noted in the current study where stainless steel and steatite indenters deformed during the fatigue test, while tungsten carbide indenters did not show any change in shape during the fatigue test (-Fig. 3). In the current study, for the standardization purpose, new indenter was used for each specimen. In addition to this, a previous study by Bhowmick et $\mathrm{al}^{14}$ found an increase in the critical load necessary to initiate cone cracks on a glass/alumina/polycarbonate trilayer structure in the tungsten carbide indenter group compared with the glass indenter group. This is said to be attributed to the presence of friction at the contact interface when indenters with high-modulus of elasticity are used. This friction can suppress the tensile stresses driving the cone cracks outside the contact, leading to an increase in the critical load. ${ }^{14}$ The above-mentioned factors might have caused the lower incidence of cone cracks on the surface of zirconia crowns fatigued with tungsten carbide, explaining possibly the higher loads needed to cause postfatigue failures in the tungsten carbide indenter group in this study. It can be argued that tungsten carbide indenters may overestimate the fracture resistance of the ceramic material, failing to reflect its actual clinical behavior. ${ }^{16}$

Unexpectedly, this study showed insignificant difference in the postfatigue fracture load between different indenter groups. These findings may initially suggest that using any of these commonly used indenter materials (stainless steel, steatite ceramic, or tungsten carbide) would not produce significantly different results compared with the other indenters. However, comparing the postfatigue fracture load of the three indenter groups with the unfatigued control group revealed a different aspect of the behavior of the zirconia ceramics under loading with the three indenters. It is also noticeable 


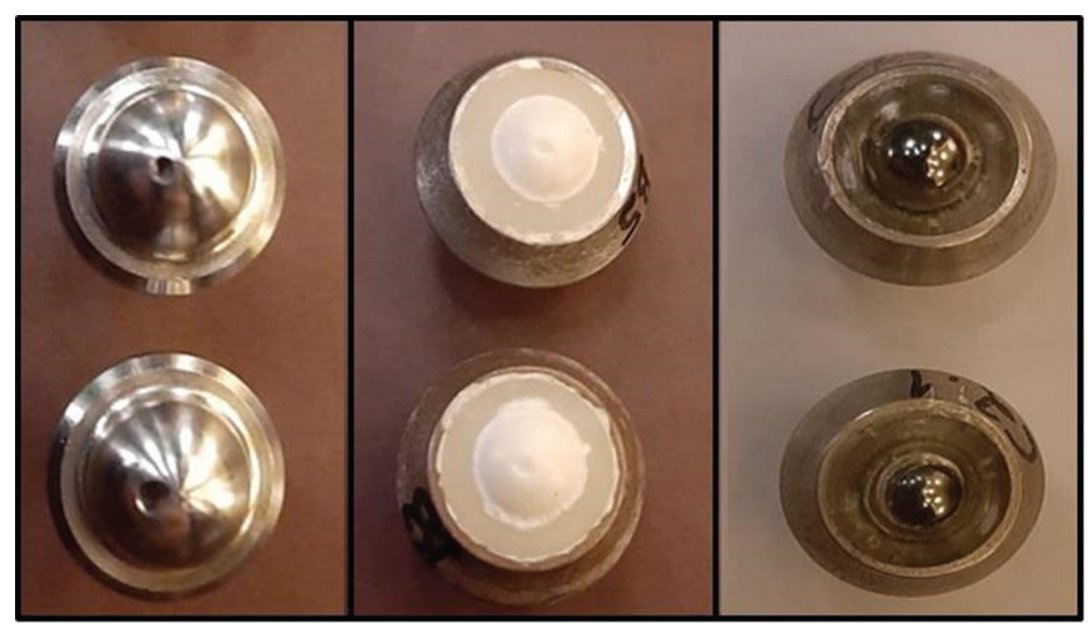

Fig. 3 Deformation in the indenters used in the application of cyclic loading; stainless steel (left), and steatite ceramic (middle) showed clear deformation compared with the tungsten carbide indenters (right).

that the stainless steel and ceramic indenters produced very close results. This may be explained by the relatively close modulus of elasticity of the two materials compared with that of tungsten carbide indenters. Therefore, using indenters that have high-elastic modulus values compared with that of natural dentition like tungsten carbide may lead to over expectation of the of the performance of zirconia in the clinical service.

On the other hand, Weber et $\mathrm{al}^{15}$ stated that the influence of using different loading pistons on the fracture resistance of ceramic materials (lithium disilicate and feldspathic porcelains) in a monotonic loading depends on the type of the ceramic material itself. They explained that the difference in the elastic modulus in different pistons will not affect fracture resistance of high-elastic modulus ceramics such as lithium disilicate. These materials are less sensitive to differences in stress distribution than ceramics with lower elastic modulus values (feldspathic porcelains). However, Weber et al ${ }^{15}$ used stainless steel, epoxy resin, lithium disilicate and human teeth antagonists, and did not include very high elastic modulus indenters such as tungsten carbide. In addition, the study design did not involve fatigue testing.

This study investigated the influence of indenter material including three commonly used indenters on fatigue and fracture resistance of zirconia crowns. Extracted human teeth were used in previous research works to achieve greater level of simulation to the clinical situation and produce a varying number of contact points during loading. ${ }^{11,22}$ However, the considerable difficulty of standardizing these antagonists and its influence on the results should not be ignored ${ }^{15}$; natural teeth show great variations in size, form, and quality. In addition, collecting good quality extracted human teeth requires extensive time and might involve ethical concerns. Therefore, natural teeth antagonists were not considered in this study.

Using epoxy resin as abutment material might be measured as a limitation because it might not perfectly reflect the mechanical behavior of the natural teeth under loading. However, as mentioned earlier, the inability to produce highly standardized abutments with the natural teeth ${ }^{15}$ encourages the simulation with a material with close modulus of elasticity. The choice of epoxy resin material was made because of its modulus of elasticity ( $3 \mathrm{GPa}$ ), which is close to the human dentine (11-20 GPa). ${ }^{23}$ Increasing the modulus of elasticity of the supporting material results in overestimation of the fracture strength. ${ }^{24-26}$ In a study by Rosentritt et al, ${ }^{11}$ the researchers found that using different abutment materials (human molar, $\mathrm{Co}-\mathrm{Cr}$ alloy, and liquid crystal polymer) can significantly influence the fracture resistance results of the fatigued restorations. Also, in a finite element study, Yucel et $\mathrm{al}^{27}$ demonstrated different stress distributions on the restoration, depending on the abutment materials; when a restoration was attached to dentin and epoxy resin die, the distribution of stresses was similar, but that was different when the restoration was bonded to a metal die. ${ }^{27}$ Therefore, epoxy resin material has been used in several previous studies $^{28-33}$ as a simulation of the natural teeth.

Further studies are required to emphasize the findings of this study. Reliable direct comparisons of the current results with previous similar studies could not be drawn due to the lack of studies evaluating the effect of using different indenters on the fatigue and postfatigue behavior of zirconia restorations. This is important because different restorative materials may behave differently to mechanical loading and may require special testing setups, depending on the material properties and failure mechanism. Further studies are also needed to develop more reliable in vitro approaches to evaluate dental restorations with more representative simulation of the complex clinical situation.

\section{Conclusion}

Antagonist material has a significant influence on fatigue and fracture resistance of zirconia restorations. Steatite ceramic and stainless steel indenters produced close results and significantly reduced the fracture load of zirconia crowns. However, the tungsten carbide indenter caused nonsignificant reduction in the fracture load of zirconia crowns. Therefore, having a significant influence on the results suggest that indenter material should be standardized across future 
research to achieve better understanding of the mechanical behavior of zirconia dental restorations, valid comparisons of the results, and reliable estimation of clinical performance.

\section{Conflict of Interest}

None declared.

\section{Acknowledgment}

This work was supported by Jordan University of Science and Technology, Irbid, Jordan.

\section{References}

1 Rashid H, Sheikh Z, Misbahuddin S, Kazmi MR, Qureshi S, Uddin MZ. Advancements in all-ceramics for dental restorations and their effect on the wear of opposing dentition. Eur J Dent 2016;10(4):583-588

2 Nayar S, Aruna U, Bhat WM. Enhanced aesthetics with all ceramics restoration. J Pharm Bioallied Sci 2015;7(Suppl 1): S282-S284

3 Kelly JR, Rungruanganunt P, Hunter B, Vailati F. Development of a clinically validated bulk failure test for ceramic crowns. J Prosthet Dent 2010;104(4):228-238

4 Yang R, Arola D, Han Z, Zhang X. A comparison of the fracture resistance of three machinable ceramics after thermal and mechanical fatigue. J Prosthet Dent 2014;112(4):878-885

5 DeLong R, Douglas WH. Development of an artificial oral environment for the testing of dental restoratives: bi-axial force and movement control. J Dent Res 1983;62(1):32-36

6 DeLong R, Douglas WH. An artificial oral environment for testing dental materials. IEEE Trans Biomed Eng 1991; 38(4):339-345

7 Kelly JR. Clinically relevant approach to failure testing of allceramic restorations. J Prosthet Dent 1999;81(6):652-661

8 Wiskott HW, Nicholls JI, Belser UC. Stress fatigue: basic principles and prosthodontic implications. Int J Prosthodont 1995;8(2):105-116

9 Galo R, Contente MM, Galafassi D, Borsatto MC. Hardness and modulus of elasticity of primary and permanent teeth after wear against different dental materials. Eur J Dent 2015;9(4):587-593

10 Nawafleh N, Hatamleh M, Elshiyab S, Mack F. Lithium disilicate restorations fatigue testing parameters: a systematic review. J Prosthodont 2016;25(2):116-126

11 Rosentritt M, Behr M, Gebhard R, Handel G. Influence of stress simulation parameters on the fracture strength of all-ceramic fixed-partial dentures. Dent Mater 2006;22(2):176-182

12 Rosentritt M, Behr M, Preis V. A critical evaluation of fatigue studies for restorative materials in dentistry. Curr Oral Health Rep 2016;3:221-228

13 Rosentritt M, Behr M, Scharnagl P, Handel G, Kolbeck C. Influence of resilient support of abutment teeth on fracture resistance of all-ceramic fixed partial dentures: an in vitro study. Int J Prosthodont 2011;24(5):465-468

14 Bhowmick S, Meléndez-Martínez JJ, Hermann I, Zhang Y, Lawn $B R$. Role of indenter material and size in veneer failure of brittle layer structures. J Biomed Mater Res B Appl Biomater 2007;82(1):253-259

15 Weber KR, Benetti P, Della Bona Á, et al. How does the piston material affect the in vitro mechanical behavior of dental ceramics? J Prosthet Dent 2018;120(5):747-754
16 Miranda JS, de Carvalho RLA, de Carvalho RF, et al. Effect of different loading pistons on stress distribution of a CAD/CAM silica-based ceramic: CAD-FEA modeling and fatigue survival analysis. J Mech Behav Biomed Mater 2019;94:207-212

17 Harvey CK, Kelly JR. Contact damage as a failure mode during in vitro testing. J Prosthodont 1996;5(2):95-100

18 Zhang Y, Lawn BR. Fatigue sensitivity of Y-TZP to microscale sharp-contact flaws. J Biomed Mater Res B Appl Biomater 2005;72(2):388-392

19 Aboushelib MN. Simulation of cumulative damage associated with long term cyclic loading using a multi-level strain accommodating loading protocol. Dent Mater 2013;29(2): 252-258

20 Qasim TQ, El-Masoud BM, Laban AMA. The effect of resistance grooves on the fracture toughness of zirconia-based crowns from mono and cyclic loading. Eur J Dent 2018;12(4):491-495

21 Rosentritt M, Hahnel S, Engelhardt F, Behr M, Preis V. In vitro performance and fracture resistance of CAD/CAM-fabricated implant supported molar crowns. Clin Oral Investig 2017;21(4):1213-1219

22 Rosentritt M, Siavikis G, Behr M, Kolbeck C, Handel G. Approach for valuating the significance of laboratory simulation. J Dent 2008;36(12):1048-1053

23 Kinney JH, Marshall SJ, Marshall GW. The mechanical properties of human dentin: a critical review and re-evaluation of the dental literature. Crit Rev Oral Biol Med 2003;14(1):13-29

24 Scherrer SS, de Rijk WG. The fracture resistance of all-ceramic crowns on supporting structures with different elastic moduli. Int J Prosthodont 1993;6(5):462-467

25 Rosentritt M, Plein T, Kolbeck C, Behr M, Handel G. In vitro fracture force and marginal adaptation of ceramic crowns fixed on natural and artificial teeth. Int J Prosthodont 2000;13(5):387-391

26 Mahmood DJ, Linderoth EH, Vult Von Steyern P. The influence of support properties and complexity on fracture strength and fracture mode of all-ceramic fixed dental prostheses. Acta Odontol Scand 2011;69(4):229-237

27 Yucel MT, Yondem I, Aykent F, Eraslan O. Influence of the supporting die structures on the fracture strength of all-ceramic materials. Clin Oral Investig 2012;16(4):1105-1110

28 Nawafleh N, Hatamleh MM, Öchsner A, Mack F. The impact of core/veneer thickness ratio and cyclic loading on fracture resistance of lithium disilicate crown. J Prosthodont 2018;27(1):75-82

29 Nawafleh NA, Hatamleh MM, Öchsner A, Mack F. Fracture load and survival of anatomically representative monolithic lithium disilicate crowns with reduced tooth preparation and ceramic thickness. J Adv Prosthodont 2017;9(6):416-422

30 Nakamura K, Ankyu S, Nilsson F, et al. Critical considerations on load-to-failure test for monolithic zirconia molar crowns. J Mech Behav Biomed Mater 2018;87:180-189

31 Badran N, Abdel Kader S, Alabbassy F. Effect of incisal porcelain veneering thickness on the fracture resistance of cad/cam zirconia all-ceramic anterior crowns. Int J Dent 2019;2019:6548519

32 Vinson L, McCrea MC, Platt JA, Sanders BJ, Jones JE, Weddell A. Fracture resistance of full ceramic primary crowns. J Dent Oral Health Cosmesis 2016; doi:10.24966/DOHC-6783/100005

33 Nordahl N, Vult von Steyern P, Larsson C. Fracture strength of ceramic monolithic crown systems of different thickness. J Oral Sci 2015;57(3):255-261 